\title{
Laparoscopic bilateral gonadectomy in a case of turner syndrome with 45X0/46XY genotype
}

\author{
Nitin H. Shah, Riddhi J. Shah*, Swapnali Kshirsagar
}

Department of Obstetrics and Gynecology, Vardann Multispeciality Hospital, Mumbai, Maharashtra, India

Received: 02 January 2018

Accepted: 31 January 2018

*Correspondence:

Dr. Riddhi J. Shah,

E-mail: rydhie@gmail.com

Copyright: (c) the author(s), publisher and licensee Medip Academy. This is an open-access article distributed under the terms of the Creative Commons Attribution Non-Commercial License, which permits unrestricted non-commercial use, distribution, and reproduction in any medium, provided the original work is properly cited.

\begin{abstract}
Turner syndrome is one of the common chromosomal aberrations which manifests in a female as multiple phenotypic disorders usually presenting as a case of primary amenorrhea. Many of these patients display mosaicism on karyotyping and a presence of $\mathrm{Y}$ chromosomal material indicates high risk of gonadoblastoma and gonadectomy is indicated which is best achieved by laparoscopy. This is a case of 21-year-old female phenotype referred as a case of primary amenorrhea diagnosed as Turner syndrome with 46XY mosaicism. Laparoscopic bilateral salpingoophorectomy was done. In patients of primary amenorrhea karyotyping should be evaluated and if Y chromosome detected these patients should be subjected to gonadectomy after proper risk counselling about malignancy.
\end{abstract}

Keywords: Gonadoblastoma, Turner, Y chromosome

\section{INTRODUCTION}

Turner syndrome is the most common chromosomal abnormality in conceptus, estimated to be $3 \%$ and a very common cause of spontaneous abortion in first trimester. As most abort spontaneously or are diagnosed thanks to prenatal ultrasound or screening markers and terminated, the estimated rate in live borns is $1: 2500$ or $1: 3000 .^{1}$

As described by Henry Turner in 1938, the syndrome consists of typical features like short stature, webbed neck, low hairline, shield chest, increased carrying angle of the elbow in a case of primary amenorrhea. The classic Turner syndrome is also associated with internal disorders like aortic coarctation, horseshoe kidney, hypothyroidism and attention deficit hyperactive disorder. Mosaicism is a common variant of turner syndrome where the syndromic characteristics may be absent or subtle. The karyotype in mosaicism is $45 \mathrm{XO} / 46 \mathrm{XX}$ or $45 \mathrm{XO} / 46 \mathrm{XY}$. Any $\mathrm{Y}$ chromosomal content can lead to formation of gonadoblastoma or dysgerminoma in the extrascrotal gonads (abdominal or pelvic or inguinal). This is also the case in partial or complete androgen insensitivity syndrome. Hence these cases when detected on karyotyping should be counselled and offered gonadectomy to protect from malignancy, the risk of which may be about $10-30 \% .^{2}$ The following case reported is of a Turner mosaic treated with laparoscopic bilateral gonadectomy.

\section{CASE REPORT}

A 21-year-old case of primary amenorrhea was referred to the centre for management. Patient was phenotypic female with a height of 152 centimetres and weight of 45 $\mathrm{kg}$, BMI of $19.47 \mathrm{~g} / \mathrm{m}^{2}$. She did not exhibit any of the classic characteristics of turner syndrome on general examination. Axillary hair was absent and pubic hair sparse. Breast development was tanner stage II, inadequate for age. There was no sign of hirsutism. 
Respiratory and cardiovascular examination was normal. Per abdomen examination was normal and on Local vulval inspection, vaginal orifice was present and there was no abnormality like clitoromegaly or imperforate hymen. Bilateral groins were palpated to exclude any inginal mass.

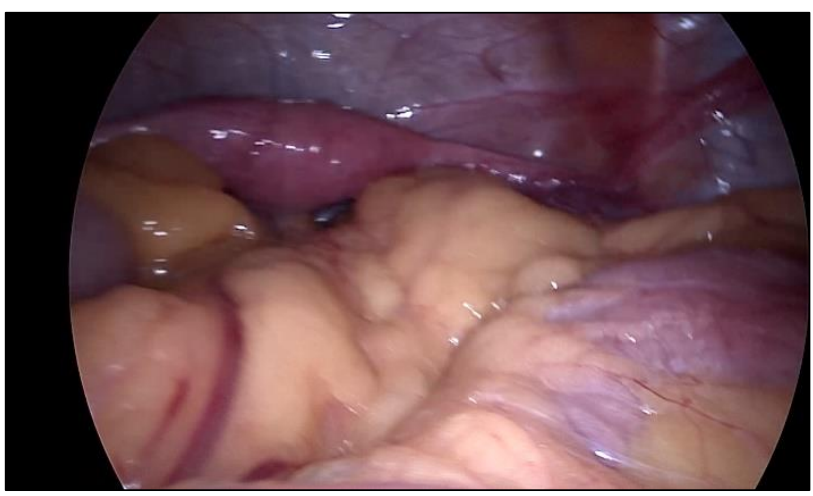

Figure 1: Intraoperative picture: Hypoplastic uterus.

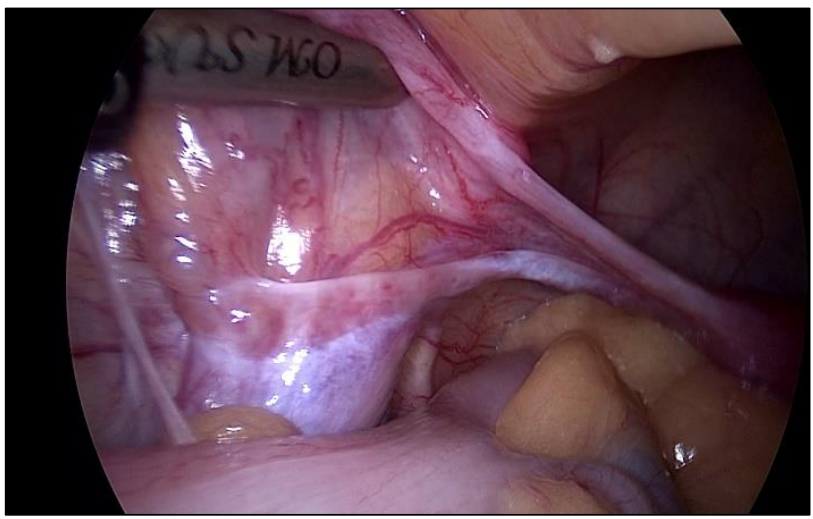

Figure 2: Left steak gonad.

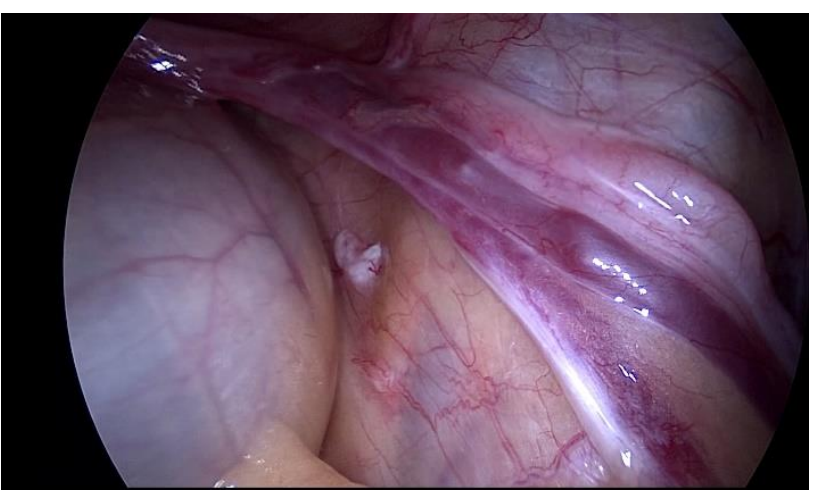

Figure 3: Right streak gonad.

The investigations done were as follows: serum TSH = $1.5 \mathrm{IU} / \mathrm{ml}$, prolacin $=4.6 \mathrm{ng} / \mathrm{ml}, \mathrm{FSH}=121 \mathrm{IU} / \mathrm{ml}$ and $\mathrm{LH}=32 \mathrm{IU} / \mathrm{ml}$, serum Testosterone $=18.41 \mathrm{ng} / \mathrm{dL}$, ultrasound of abdomen was normal, ultrasound pelvis showed hypoplastic uterus measuring $3.6 \times 1.1 \times 0.7 \mathrm{~cm}$ and both ovaries not visualised, karyotyping revealed mosaicism with cell of $45 \mathrm{XO}$ lineage (Turner genotype) and of 46XY lineage (normal male genotype). 2D-ECHO of the heart done and coarctation of aorta ruled out.

Patient and her parents were informed about the condition, the risk of malignancy, the need for gonadectomy and the postoperative need of hormone therapy for sexual characters and the subsequent need of surrogacy or adoption. After thorough counselling a laparoscopic surgery was planned after consulting anaesthetists and physicians regarding surgical fitness.

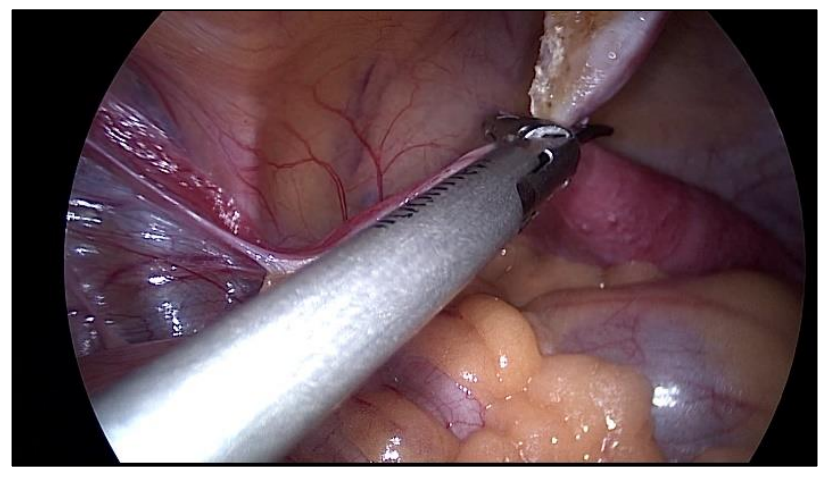

Figure 4: Left salpingoophorectomy with harmonic scalpel.

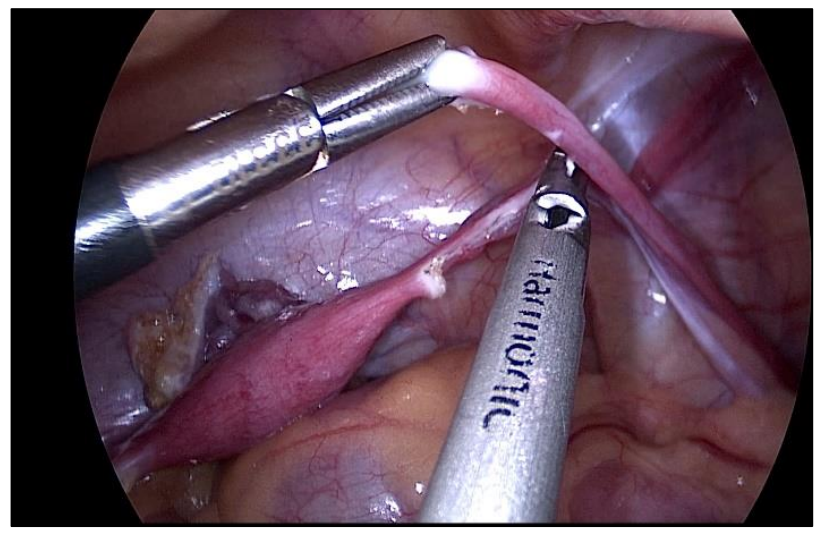

Figure 5: Right salpingoophorectomy with harmonic scalpel.

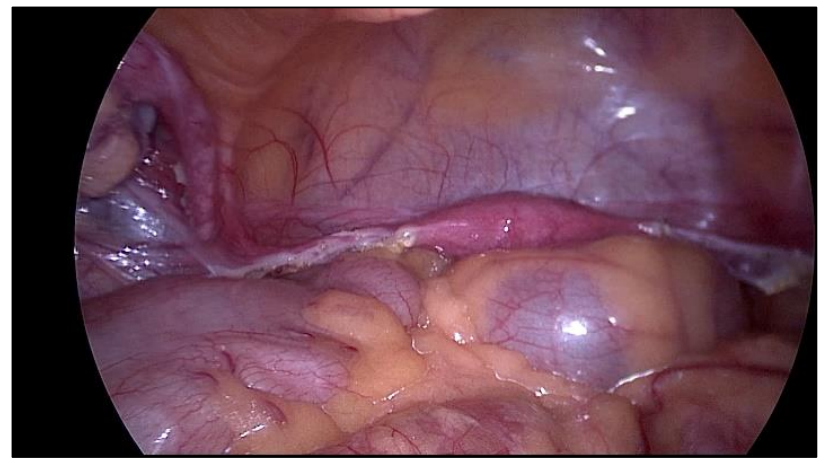

Figure 6: Postoperative picture.

Patient was taken under spinal anaesthesia with sedation in a flat lithotomy position. Primary port was $10 \mathrm{~mm}$ 
supraumbilical trocar inserted by direct entry technique and two accessory $6 \mathrm{~mm}$ ports introduced under vision on left side of the abdomen-lower at appoint $2 \mathrm{~cm}$ medial and superior to anterior inferior iliac spine and upper at a point $10 \mathrm{~cm}$ above the lower. Operative pressure was kept at $10 \mathrm{mmHg}$ throughout. In situ findings revealed a ridge like hypoplastic uterus in the centre with stretched out round ligaments and ovarian ligaments. Bilateral fallopian tubes were elongated, and bilateral ovaries were small and adherent the mesosalpinx, appeared as streak gonads. A bilateral salpingoohorectomy was performed by lifting up the fimbrial end of the fallopian tubes and using harmonic scalpel to cut the mesosalpinx and ovarian ligament at the cornu. Haemostasis checked, and instruments removed. Ports closed with skin staplers.

Patient's condition was normal postoperative, and she was discharged on day 3 and advised combined oral hormonal pills. Histopathology was done, and report showed atretic follicles and no evidence of malignancy.

\section{DISCUSSION}

Mosaicism is a common finding in karyotyping in cases of Turner's syndrome and there are many variants. A study conducted in Denver showed that out of 166 clinically diagnosed Turner's syndrome, 67 exhibited mosaicisms on karyotypic testing, of which 8 showed Y chromosome cell lines. Thus, the incidence of $\mathrm{Y}$ chromosomal mosaicism was estimated to be about $4.8 \%$. In another study at University of Bologna, Italy, 101 patients with Ullrich-Turner syndrome diagnosed cytogenetically and followed up to puberty, Ychromosomal material including SRY and Y-centromeric DYZ3 repeats was found in 14 patients $(8 \%)$ and of 12 who underwent gonadectomy, gonadoblastoma was detected in four and in two more patients Y-material was detected only at molecular analysis. At conventional cytogenetic analysis, one was included in the $45, \mathrm{X}$ group and one in the $\mathrm{X}+$ mar group. Of the cases detected with malignancy, one had also an immature teratoma and an endodermal sinus carcinoma. This study showed a higher percentage $(9.4 \%)$ of Y-chromosomal material as detected by molecular analytic techniques and a prevalence of gonadoblastoma with Y-positive material of $33.3 \%$ so also the presence of other gonadal malignancies. ${ }^{4}$ It shows that these patients will definitely benefit from molecular screening methods to detect the $\mathrm{Y}$ component like FISH or PCR and PCR continues to be a rapid, highly sensitive, easy-to-perform and inexpensive tool with the benefit of requiring lesser sample.

The role of the $\mathrm{Y}$ chromosome in oncogenesis is still understudied. Although gonadoblastoma is benign usually, it can transform to invasive dysgerminoma or other malignancies in $60 \%$ patients. Although some authors have questioned the high incidence of gonadoblastoma (around 30\%), any kind of risk justifies investigation of $\mathrm{Y}$-chromosome sequences in these patients. The unpredictable risk of developing gonadoblastoma or other tumors as well as an unpredictable malignant behaviour of the disease, also a potential risk of virilization during puberty necessitate gonadectomy. ${ }^{5}$

Fertility preservation is not an issue and these patients require oocyte donation and if conceive are high risk pregnancy to manage with aortic coarctation and risk of aortic dissection and 2\% mortality risk. The American society for reproductive medicine (ASRM) recommended Turner to be a relative contraindication for pregnancy and an absolute contraindication if the patient has a documented cardiac anomaly. ${ }^{6}$ Thus in another study 3 such patients with Y-chromosome were advised gonadectomy and laparoscopy considered as the best modality of surgery to reduce operative morbidity. And in one of these gonadoblastoma was detected in the streak gonads on histopathology. ${ }^{7}$

A metaanalysis in 1986 showed that gonadal malignancies occurred almost exclusively in dysgenetic gonads with abnormal chromosomes, however exploratory laparotomy and gonadectomy with also hysterectomy was advocated in that era as early as possible. ${ }^{8}$ With the advent of endoscopy these cases underwent less surgical morbidity and the advent of artificial reproductive techniques made it possible for the uterus to be preserved for fertility by oocyte donation.

The first case performed using minimal invasive techniques was in 1991 and the second in 2000. However very few such cases operated laparoscopically have been reported and hardly any from India. ${ }^{9}$

Controversy lies in the timing of gonadectomy as 15-40\% of these patients undergo spontaneous puberty and $2-10 \%$ may have spontaneous menarche. However, gonadectomy must be performed at the earliest due to malignant potential. Hormone therapy may be started at 12-13 years of age after waiting for spontaneous puberty as most of these patients have premature ovarian failure. ${ }^{10}$

As against patients of complete androgen insensitivity syndrome in whom the controversy is more profound as gonadectomy can be deferred till after puberty and they can rely on androgens from gonads to develop female secondary sexual characters. This is so as the risk of malignancy before puberty is $5.5 \%$ and increases after puberty to reach $33 \%$ at the age of 50 years and it is higher in partial androgen insensitivity of about $15 \% .^{11}$ Prophylactic gonadectomy is indicated at an optimal age of 16-18 years by most studies in these patients. ${ }^{2}$

In regards the controversy of performing salpingoophorectomy versus oophorectomy alone, a survey by paediatric endocrinologists showed that most surgeons preferred laparoscopy (96\%), of which $46 \%$ opted for oophorectomy while $26 \%$ preferred salpingooophorectomy and $27 \%$ used either. The experienced surgeons favoured salpingoophorectomy in 
these patients. However, in this study where 54 surgeons responded it was concluded that there is no consensus with respect to removal of fallopian tubes. ${ }^{12}$ However, removal of fallopian tubes along with the streak gonads is technically easier, prevents future hydrosalpinx or other tubal pathologies and also prevents ectopic pregnancy with artificial reproduction in these patients.

\section{CONCLUSION}

To conclude, it is crucial that cases of primary amenorrhea undergo karyotyping and those with Ychromosomal dysgenetic gonads are offered early gonadectomy, most preferably by laparoscopy as the benefits include early discharge and early return to routine and social activities and better cosmesis in these young patients.

\section{Funding: No funding sources}

Conflict of interest: None declared

Ethical approval: Not required

\section{REFERENCES}

1. Wong AS, Yuen P. Laparoscopic gonadectomy in patients with mosaic turner syndrome and complete androgen insensitivity syndrome: a report of 2 cases and review of the surgical aspects. J Minim Invasive Surg Sci. 2013;2(4):62-6.

2. Liu AX, Shi HY, Cai ZJ, Liu A, Zhang D, Huang $\mathrm{HF}$, et al. Increased risk of gonadal malignancy and prophylactic gonadectomy: a study of 102 phenotypic female patients with Y chromosome or Y-derived sequences. Hum Reprod Adv Access Publ. 2014;29(14):1413-91.

3. Brant WO, Rajimwale A, Lovell MA, Travers SH, Furness PD, Sorensen M, et al. Gonadoblastoma and Turner Syndrome. J Urol. 2006;175(5):1858-60.

4. Mazzanti L, Cicognani A, Baldazzi L, Bergamaschi R, Scarano E, Strocchi S, et al. Gonadoblastoma in Turner syndrome and Y-chromosome-derived material. Am J Med Genet Part A. 2005;135A(2):150-4.
5. Oliveira RMR de, Verreschi IT do N, Lipay MVN, Eça LP, Guedes AD, Bianco B. Y chromosome in Turner syndrome: review of the literature. Sao Paulo Med J. 2009;127(6):373-8.

6. Practice Committee of American Society for Reproductive Medicine. Increased maternal cardiovascular mortality associated with pregnancy in women with Turner syndrome. Fertil Steril. 2012;97(2):282-4.

7. Tokmak A, Akselim B, Yeşilyurt H. Turner syndrome with 45X/46XY mosaicism underwent gonadectomy: report of 3 cases. East $\mathrm{J}$ Med. 2015;20:117-9.

8. Troche V, Hernandez E. Neoplasia arising in dysgenetic gonads. Obstet Gynecol Surv. 1986;41(2):74-9.

9. Kawabata G, Sato M, Okamoto Y, Mizuno Y, Akematsu T, Okada H. Laparoscopic removal of gonads in a Turner's syndrome mosaic female patient with isodicentric Y chromosome. Int J Urol. 2000;7(11):425-6.

10. Ackermann A, Bamba V. Current controversies in turner syndrome: genetic testing, assisted reproduction, and cardiovascular risks. J Clin Transl Endocrinol. 2014;1(3):61-5.

11. Nakhal RS, Hall-Craggs M, Freeman A, Kirkham A, Conway GS, Arora R, et al. Evaluation of retained testes in adolescent girls and women with complete androgen insensitivity syndrome. Radiol. 2013;268(1):153-60.

12. Shankar KR, Inge TH, Gutmark-Little I, Backeljauw PF. Oophorectomy versus salpingo-oophorectomy in Turner syndrome patients with Y-chromosome material: clinical experience and current practice patterns assessment. J Pediatr Surg. 2014;49(11):1585-8.

Cite this article as: Shah NH, Shah RJ, Kshirsagar S. Laparoscopic bilateral gonadectomy in a case of turner syndrome with 45XO/46XY genotype. Int $\mathrm{J}$ Reprod Contracept Obstet Gynecol 2018;7:1285-8. 